SchemanN, M., Ehrlein, H. J. and Sahyoun, H. (1985) Computerised method for pattern recognition of intestinal motility: functional significance of the spread of contractions. Med.\& Biol. Eng. \& Comput., 23, 143-149.

Schuurkes, J. A. J., van der Schee, E. J., Grashuis, J. L. and Charbon, G. R. A. (1977) Calibration of strain gauge force transducers and quantification of gastric motility. In Gastrointestinal motility in health and disease. DuthIE, H. L. (Ed.), Proc. 6th Int. Symp. on Gastrointestinal Motility, MTP Press, Lancaster, UK, 647-654.

SchuUrkes, J. A. J. and VAN Nueten, J. M. (1984a) Gastroduodenal coordination. In Gastric and gastroduodenal motility. Akkermans, L. M. A., Johnson, A. G. and Read, N. W. (Eds.), Surgical Science Series, Praeger, Vol. 4, 193-127.

SchuUrkes, J. A. J. and VAN Nueten, J. M. (1984b) Control of gastroduodenal coordination: dopaminergic and cholinergic pathways. 2nd Int. Symp. on Duodengastric Reflux, Brunner, Switzerland, 23rd-25th June 1983, Scand. J. Gastroenterol., 19, Suppl. 92, 8-12.

SchuUrkes, J. A. J., Akkermans, L. M. A. and Van Nueten, J. M. (1984) Stimulating effect of cisapride on antroduodenal motility in the conscious dog. In Gastrointestinal motility. Roman, C. (Ed.), Proc. 9th Int. Symp. Gastrointestinal Motility, Aix-en-Provence, Sept. 1983, MTP Press, Lancaster, UK, 95-102.

SchuURKes, J., DE RIDder, W., Voeten, J., Eelen, J. and VAN NuETEN, J. M. (1988) Analysis of upper small intestinal motor patterns in conscious dogs: effect of cisapride (Abstract). Workshop on Computer Analysis of Small Intestinal Motility Recording, 2nd-3rd Oct. 1987, Stuttgart-Hohenheim.

WINGATE, D. L. and BARNETT, T. (1978) The logical analysis of the electroenterogram. Dig. Dis., 23, 553-558.

\section{Authors' biographies}

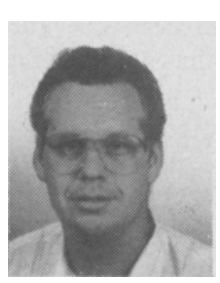

Walter De Ridder was born in 1954 in Antwerp, Belgium. There he studied at the PHTIS, where he received a degree in Medical Chemistry in 1977. He works in the Department of Gastrointestinal Pharmacology of the Janssen Research Foundation. He is especially interested in the combination of computer applications with in vitro/in vivo models for studying gastrointestinal motility.

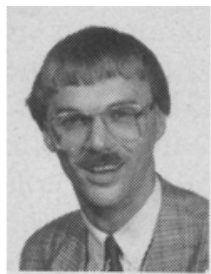

Jan Voeten was born in 1959 at Beerse, Belgium. He studied Electronics at the KIHA college of Hoboken, where he received the degree of Electronical Engineer in 1981. He is currently a member of the Scientific Instruments Division of Janssen Pharmaceutica. His work mainly consists of development and implementation of microcomputer-based measuring and reporting instruments for the Janssen Research departments.

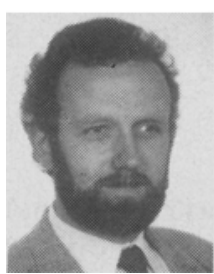

Jef Rombouts was born in 1952 at Hoogstraten, Belgium. He studied Electronics at the KHIH college of Geel, where he received the degree of Electronical Engineer in 1975. He started as a digital instrument designer, became leader of the analogue instruments group and is currently the head of the Scientific Instruments Division of the Janssen Research Foundation. His research interests include the instrument/computer synergy which can result in integrated laboratory systems.

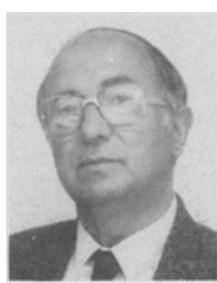

Jan M. Van Nueten was born in 1926 in Loenhout, Belgium. He graduated with the degree of Doctor of Sciences (Physiology) at the University of Paris (Sorbonne). He is currently a member of the Executive Board of the Janssen Internal Research Council. His main scientific interests are gastrointestinal and cardiovascular research.

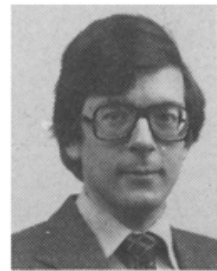

Jan Schuurkes was born in 1950 in Oisterwijk, The Netherlands. He studied Biochemistry and Pharmacology at the Universities of Nijmegen and Utrecht, where he received a doctoral degree (Ph.D.) in Medicine in 1978. He joined Janssen Pharmaceutical Research Laboratories in 1979 at the Department of Pharmacodynamics and is currently heading the Department of Gastrointestinal Pharmacology. His interest is the pharmacology of gastrointestinal motility.

\title{
Erratum
}

Medical \& Biological Engineering \& Computing, Vol. 27, No. 3, May 1989, 281-287.

'Improved photomultiplier tube for positron emission tomography' by T. Woldeselassie

Four textual errors have been discovered in the above paper: a typographical error in defining a mathematical quantity, two missing brackets in equations and a wrong reference cited.

On page 282 , eqn. 5 and the subsequent text should have read:

$$
d=0 \cdot 2\left(V_{a}\right)^{0 \cdot 7}
$$

gives the dependence of $d$ on the interdynode potential $V_{a}$ (HAMilton, 1977).

On page 283, eqn. 10 and its following equation should have read:

$$
\begin{aligned}
i_{k}(t)= & u(t) I_{s}\left[1-\exp \left(-t / a_{1}\right)\right]-V_{s} C\left\{u\left(t-t_{1}\right)\right. \\
& \times \exp \left[-\left(t-t_{1}\right) / a_{2}\right]-u\left(t-t_{2}\right) \\
& \left.\times \exp \left[-\left(t-t_{2}\right) / a_{2}\right]\right\} /\left[r_{k}\left(C+C_{k}\right)\right]
\end{aligned}
$$

The current $i_{k}\left(t_{2+}\right)$ immediately after switch-off is given by

$$
i_{k}\left(t_{2+}\right)=I_{s}+V_{s} C\left[1-\exp \left(-T / a_{2}\right)\right] /\left[r_{k}\left(C+C_{k}\right)\right]
$$

On page 283 , the sentence beginning on line 13 should have read:

The photon yield is 4.8 per $\mathrm{keV}$, and the scintillation decay time (that required for the emission of 67 per cent of the light) is $300 \mathrm{~ns}$ (Sorenson and Phelps, 1987). 